\title{
Diagnosing methods common rail fuel injectors
}

Article describes diagnose and research methods Common Rail system fuel injectors. Profesional diagnose modern fuel injectors is very dificult procedure. Basic theirs work parameter influencing on correctly work parameters are magnitude injection and return dosages by definite pressures prevailing in system and injetion times. Sometimes dosages during diagnose by coordinate task and actual fuel injector are correct but engine work is not proper. So that during diagnose should extend tests procedure in range varie work conditions. Fuel injectors work characteristics are one of method researching in whole range work. During researches has been used Continental fuel injector.

Key words: CI engine, Common Rail system, fuel injector, high and low pressure system, engine diagnose, fuel combustion

\section{Introduction}

Common Rail fuel injection system is very compound diagnosing process. These system assembles with many cooperating elements. There are apart from injection, intake, exhaust systems and everything is steered by engine controller with sensors and actuators. These whole system controls CI - engine work. When there are starting faults, diagnostic process begins with engine computer test, which not only rely on memory errors but actual parameters (if the engine work). It happens often that engine during vehicle test doesn't work, then one should suggest memory faults of controller. If actual parameters analysis and memory errors indicate that injection system is defected it should be whole low and high pressure system elements checked. One of the most exposes on damages whole system element is fuel injector. Its main tasks are spray and distribute fuel in combustion chamber at a given work moment. Injector nozzle influences on spraying and distributing quality. If injections holes are damage or pollute, work quality is deteriorated. Toxic substances in fumes increasing and whole combustion process is disrupt. The second factor influences on combustion process are injection dosages. There are injection and return dosages main work parameters of fuel injector. If these factors change outside of correct limits injector is fault. On these influence use precision elements and rest elements (springs, pads, inner sealers). The most reasons to speeding up use these elements are pollution and damp in fuel. So fuel injection diagnostic process should be investigate as quality and quantity.

\section{Analysis modern fuel injectors construction solutions}

There are known many varies classification modern Common Rail system fuel injectors [4]. But for something research, diagnose and repair possibility there is simply divide it as repairable and not repairable. Every fuel injector could be diagnose, but unfortunately on account of repair technology and original spare parts lack not every could be repair. It could be use fuel injectors producers like Bosch, Delphi, Denso and Continental in motor vehicles [2]. Bosch, Denso and Delphi companies produce electromagnetic and piezoelectric injectors and Continental company only piezoelectric [6]. It could be repair practically all electromagnetic injectors. Bosch fuel injectors generations
1.0, 2.0, 2.1, 2.2 and Delphi electromagnetic there are original spare parts and repair technology, injectors Bosch generations 2.16, 2.5 there are not original repair technology and spare parts but these injectors could be disassembly, clean, to seal and assembly. The same situation is with electromagnetic Denso injectors. There is no repair technology and original spare parts but it could be improve technical conditions. It is differently with piezoelectric injectors [5]. Delphi and Denso are not repairable, with Bosch it is hard to repair because of getting air in, and with Continental is a possibility to repair but difficult to regulate. There are original spare parts to Continental fuel injectors. Figure 1 presents piezoelectric Bosch fuel injectors.

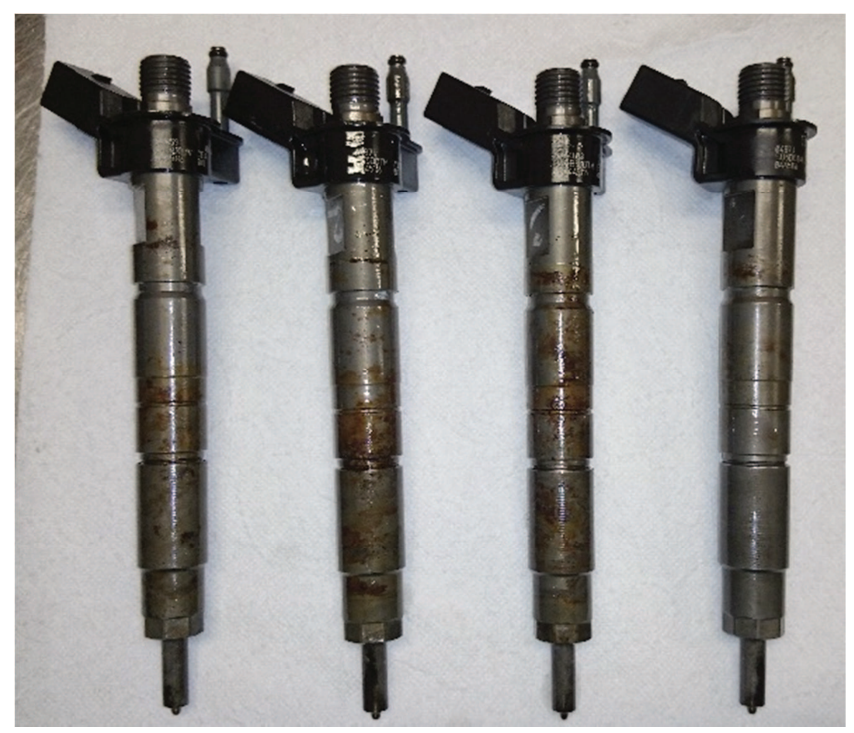

Fig. 1. Piezoelectric Bosch fuel injectors

Piezoelectric Bosch fuel injectors are signed with numbers $0445115 x x x, 0445116 x x x$ or $0445117 x x x$. There are various generations $3.1 ; 3.2$ and 3.3. This type of injectors are not repairable. Figure 2 presents disassembly on spare parts piezoelectric Bosch fuel injector.

Figure 3 presents electromagnetic Bosch fuel injector. These type of injectors are marked with number 0445110xxx CRI (cars) and 0445120xxx CRIN (lorries). 


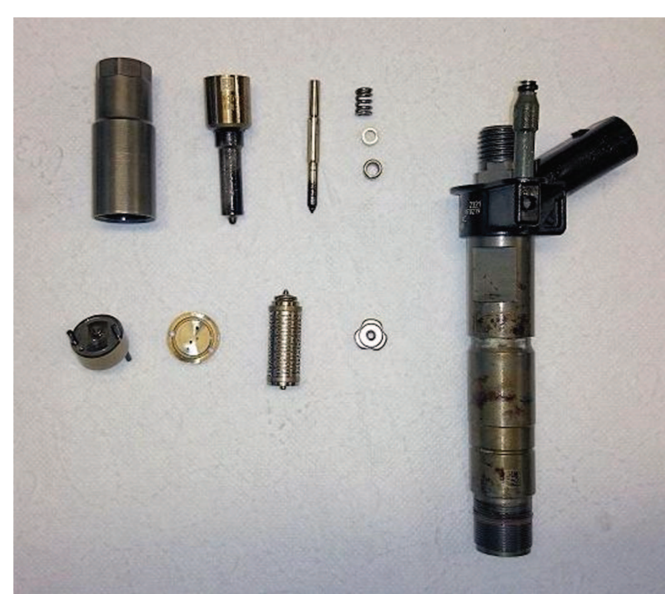

Fig. 2. Piezoelectric Bosch fuel injector disassemble on spare parts

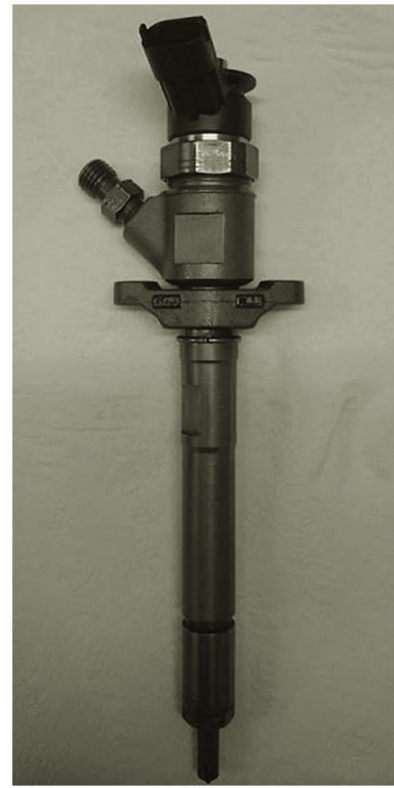

Fig. 3. Electromagnetic Bosch fuel injector

Figure 4 presents electromagnetic Bosch fuel injector generation 2.1 disassembly on spare parts. CRI and CRIN injectors are built very similar. The differences are in magnitude of injection dosages. CRIN fuel injectors have larger on account of bigger engines. The most faulty elements are precision vapours on injector needle and steering piston. The leakage magnitude influence on injection and return dosages[1]. Fuel injector with worn out steering piston and nozzle is hard to regulate.

Figure 5 shows Continental VDO Siemens fuel injector. This type of injectors are very hard to regulate during folding up. The regulation comes down to screw the valve and piezoelectric element with appropriate torque. The range of correct torque is very small that's why these type of injectors very hard to regulate.

Figures 6 and 7 present electromagnetic and piezoelectric Denso fuel injectors. There are not many piezoelectric Denso fuel injectors in CI - engines. The most often it can be meet electromagnetic (Fig. 6B). These type of electromagnetic injectors are very similar to Bosch. It is easy to disassemble and repair in spite of lack of original spare parts.

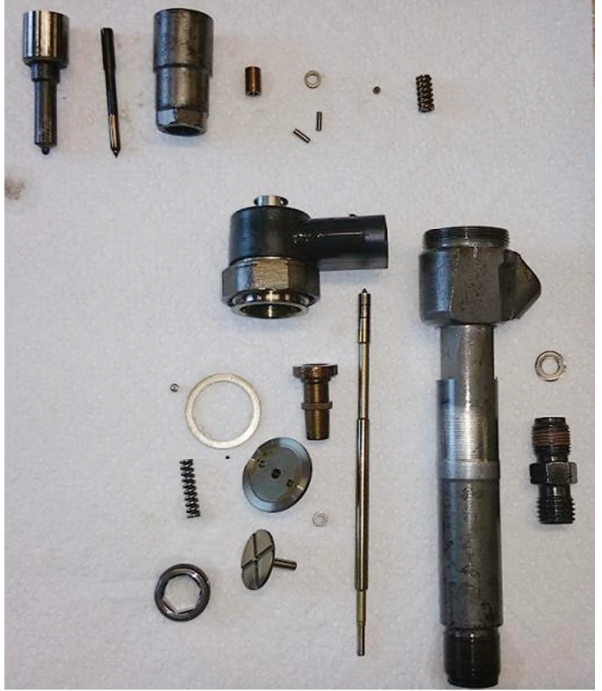

Fig. 4. Electromagnetic Bosch fuel injector gen. 2.1 disassemble on spare parts

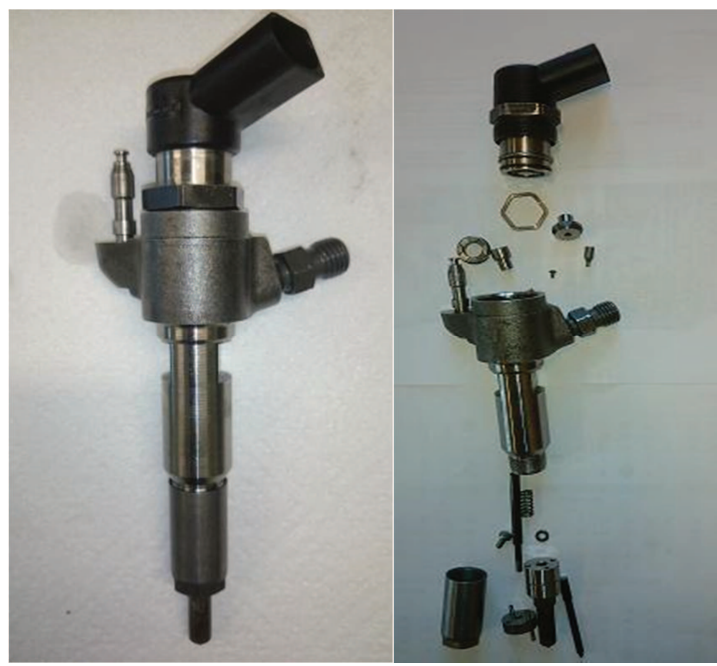

A

$\mathrm{B}$

Fig. 5. A - Piezoelectric Continental VDO Siemens fuel injectors, B - Continental fuel injector disassembly on spare parts

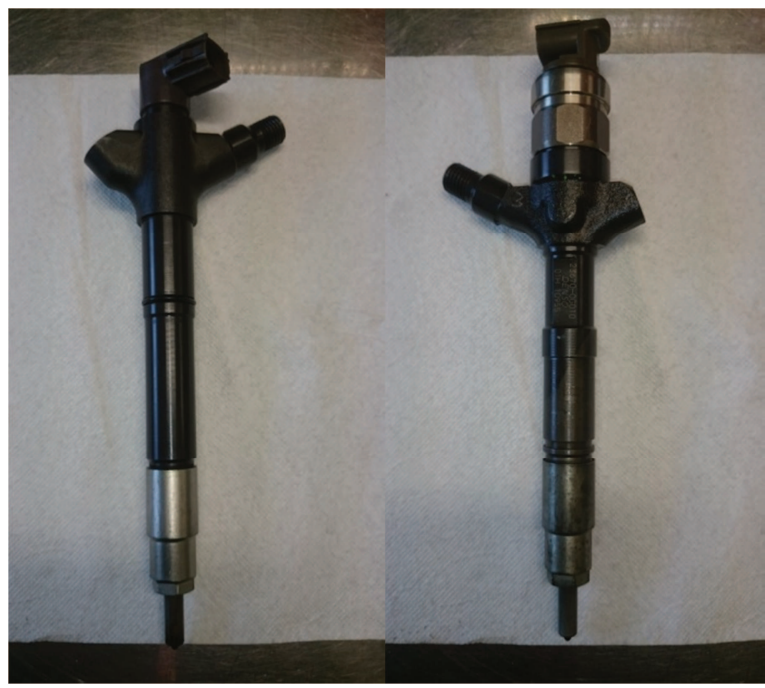

A B

Fig. 6. Denso fuel injectors A - piezoelectric, B - electromagnetic 


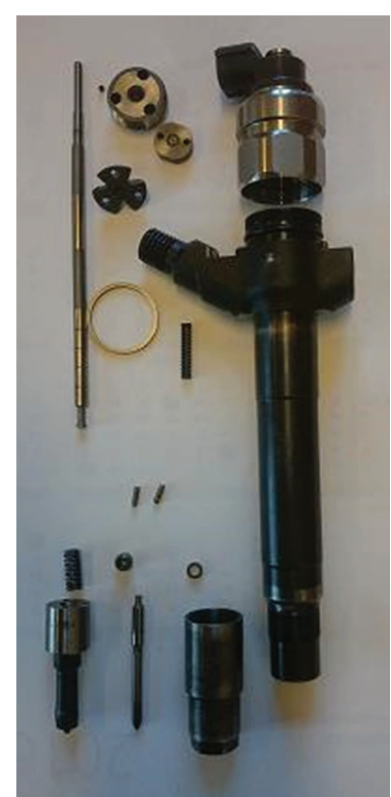

Fig. 7. Electromagnetic Denso fuel injector disassembly on spare parts

Figure 8 presents electromagnetic Delphi fuel injector. These injector is very fast because of light valve. This is very important to create more dosages during one work cycle. Negative feature is easy valve damages. This construction is very light and delicate. Delphi injection systems need very good fuel quality and to clean whole system very often.

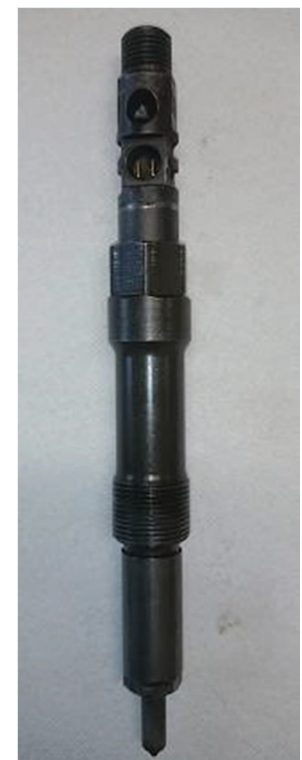

A

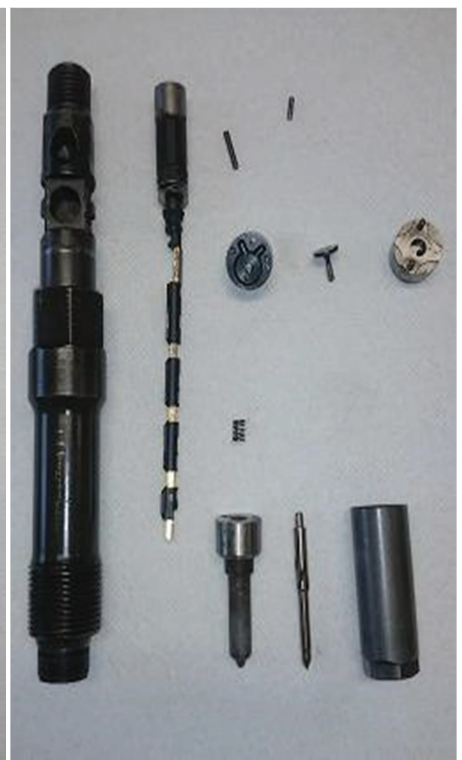

B
Fig. 8. A - electromagnetic Delphi fuel injectors, B - electromagnetic Delphi fuel injector disassembly on spare parts

Bosch and Denso electromagnetic fuel injectors are similarly. There is possibility to regulate and repair both of them. The same situation is with electromagnetic Delphi injectors. Considerable difference between these injectors is construction. Electromagnetic Delphi fuel injector has very light steering valve therefore has shorter time of injection delay. Different situation is with piezoelectric fuel injectors. There is no technology to repair them. It is possible only to testing and eventually cleaning. Piezoelectric elements are very sensitive for work condition. It is very easy to damage them. For example piezoelectric Bosch fuel injectors get air in because of wrong engine dismantling. Continental fuel injectors are very easy to disassemble than clean and put together. The problem with them is very hard to regulate injection and return dosages because of precision screw in valve and piezoelectric element. Piezoelectric injectors have very short injection delay. Thanks to this feature generate more dosages on one engine work cycle. To high dosages divergence cause wrong engine work.

\section{Diagnosing methods modern fuel injectors}

Fuel injectors research process is looked into in two aspects. When the vehicle engine work or couldn't be turn on. If the engine works it is checked return dosages and actual engine parameters by using engine diagnostic scanner. If the actual parameters indicates not correct working fuel injectors, it is necessary to dismount and research on test bench. By not working vehicle it can be only read faults on engine diagnostic scanner. When faulty indicate on fuel injectors they are dismounted and test. There is very important to check every injection and return dosages. There are many instances that injectors on normal research test worked correctly but engine didn't work good and diagnose indicate on fuel injectors [3]. Then should make detailed injector research. It relies on making injector work characteristics. There are analytical methods of researching fuel injectors. These methods relies on calculating the magnitudes of injection dosages. These approaches are not correct because it is impossible to calculate and forecast injector work parameters. Fuel injector is the physical object compound with many elements and works in huge range of pressures and injection times. During defect faulty works only separate area very often. To find faulty area it is necessary to make injector work characteristic for example initial dosages. It has been researched engine with Continental injectors. There was a problem with irregular engine work between 1300-1800 $\mathrm{min}^{-1}$. Engine diagnose indicates on fuel injectors failure. The standard test of fuel injectors was the first stage researches (Fig. 9). The results indicated that injectors were correctly therefore it has been made fuel injectors work test for initial dosages (Fig. 10-20). Initial dosages occur for very short injection time about $200 \mu \mathrm{s}$ for various engine work conditions. Improper value causes deteriorating of combustion process. Figures shows that first injector had considerable higher dosages of the rest. It is noticeable on Fig. 12-16. Than it has been made two injectors work characteristics but only in initial and neutral gear dosages area (Fig. 21 and 22). Researches show that first injector had increased dosages values especially in range 200-400 $\mu$ s. There is noticeable decrease of dosages values above injection time $450 \mu$ s particularly for injection pressures 45-55 MPa. 


\section{Standard fuel injector research}

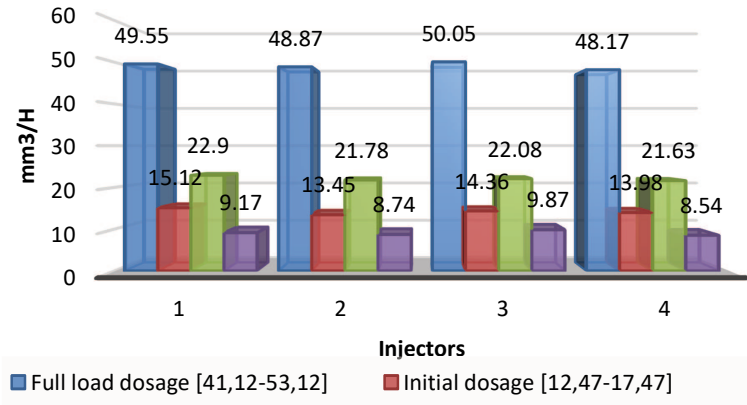

$\square$ Medium load dosage $[17,19-29,19] \square$ Idling speed dosage $[7,31-12,31]$

Fig. 9. Results of standard fuel injectors research

Injection dosages

Pressure: $20 \mathrm{MPa}$, Injection time $200 \mu$ s, Frequency $20 \mathrm{~Hz}$ Injection number 1000

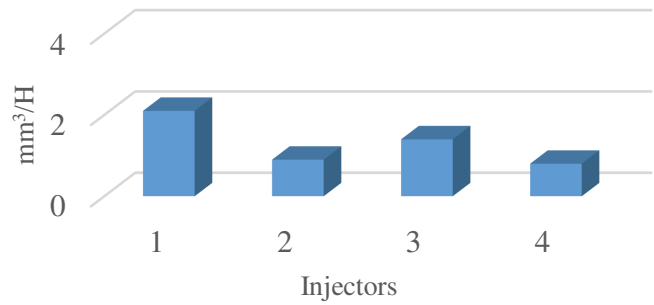

Fig. 10. Injector work test results. Pressure $20 \mathrm{MPa}$, injection time $200 \mu \mathrm{s}$

Injection dosage

Pressure: $30 \mathrm{MPa}$, Injection time $200 \mu$ s, Frequency $20 \mathrm{~Hz}$, Injection number 1000

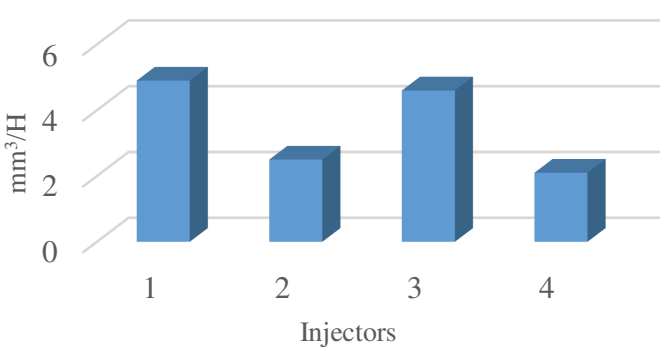

Fig. 11. Injector work test results. Pressure $30 \mathrm{MPa}$, injection time $200 \mu \mathrm{s}$

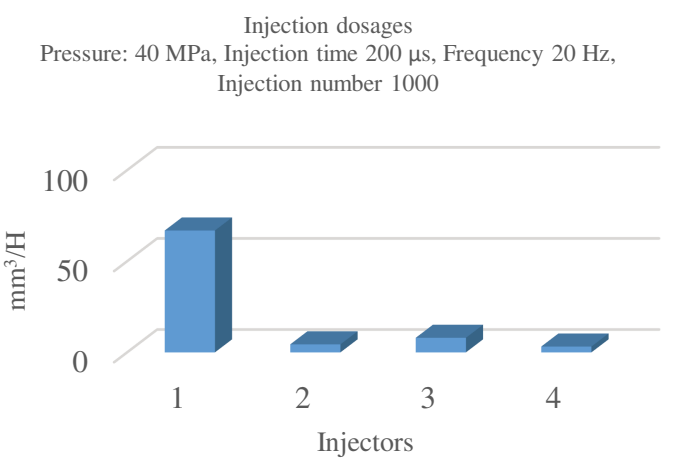

Fig. 12. Injector work test results. Pressure $40 \mathrm{MPa}$, injection time $200 \mu \mathrm{s}$
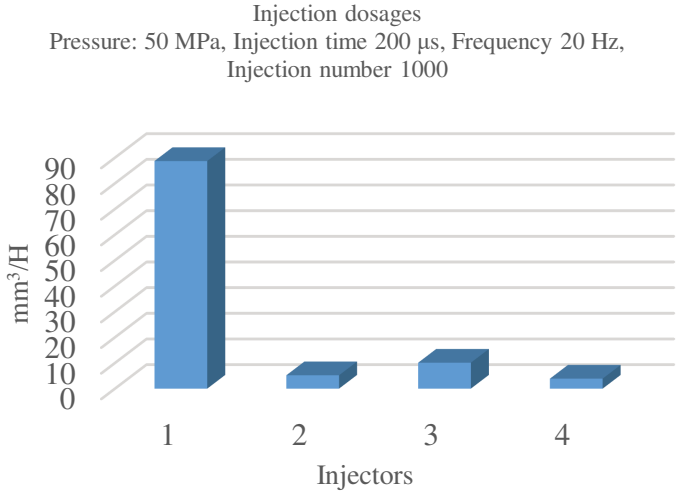

Fig. 13. Injector work test results. Pressure $50 \mathrm{MPa}$, injection time $200 \mu \mathrm{s}$

Injection dosage

Pressure: $60 \mathrm{MPa}$, Injection time $200 \mu$ s, Frequency $20 \mathrm{~Hz}$ Injection number 1000

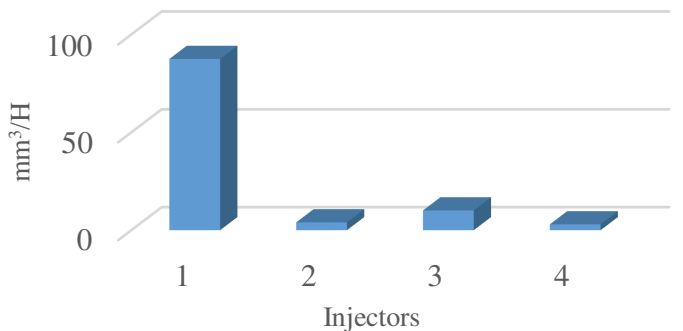

Fig. 14. Injector work test results. Pressure $60 \mathrm{MPa}$, injection time $200 \mu \mathrm{s}$

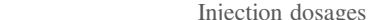

Pressure: $70 \mathrm{MPa}$, Injection time $200 \mu$ s, Freuency $20 \mathrm{~Hz}$, Injection number 1000

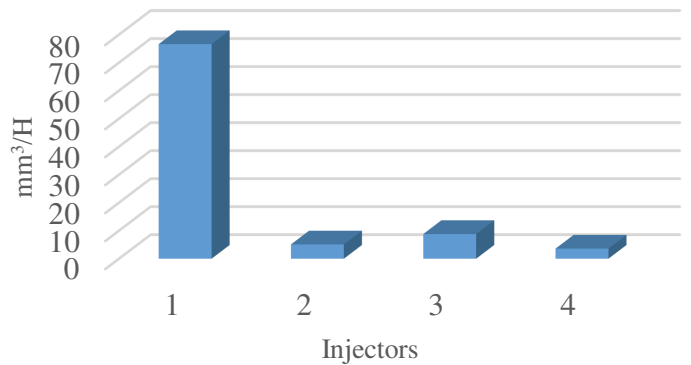

Fig. 15. Injector work test results. Pressure $70 \mathrm{MPa}$, injection time $200 \mu \mathrm{s}$
Injection dosages

Pressure: $80 \mathrm{MPa}$, Injection time $200 \mu \mathrm{s}$, Frequency $20 \mathrm{~Hz}$, Injection number 1000

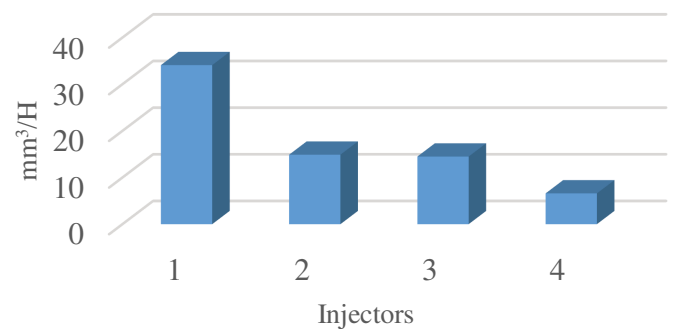

Fig. 16. Injector work test results. Pressure $80 \mathrm{MPa}$, injection time $200 \mu \mathrm{s}$ 


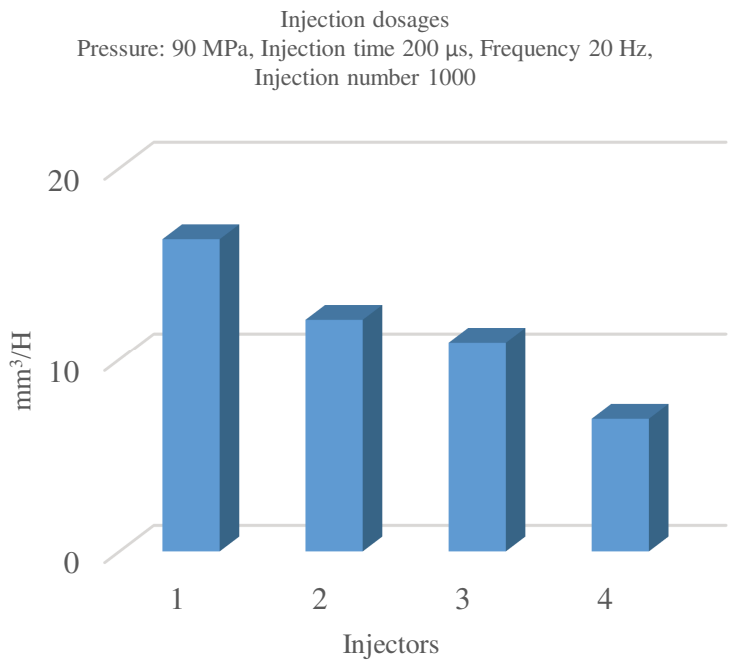

Fig. 17. Injector work test results. Pressure $90 \mathrm{MPa}$, injection time $200 \mu \mathrm{s}$

Injection dosages
Pressure: $100 \mathrm{MPa}$, Injection time $200 \mu \mathrm{s}$, Frequency $20 \mathrm{~Hz}$,
Injection number 1000 Injection number 1000

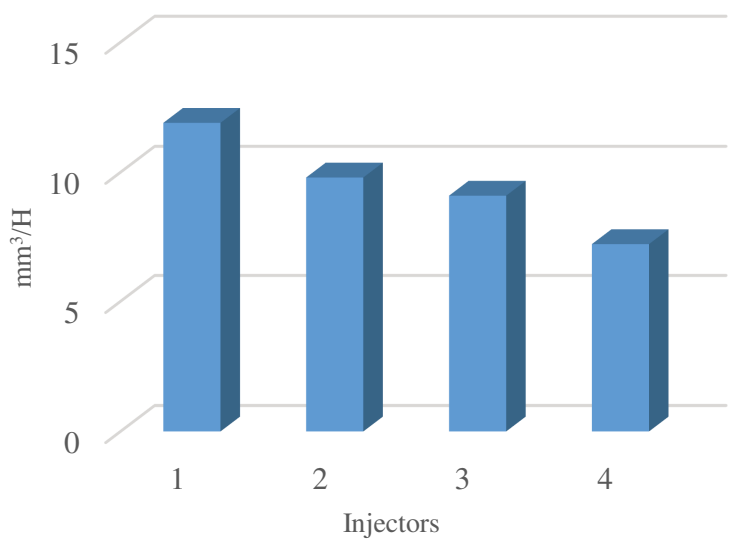

Fig. 18. Injector work test results. Pressure $100 \mathrm{MPa}$, injection time $200 \mu \mathrm{s}$

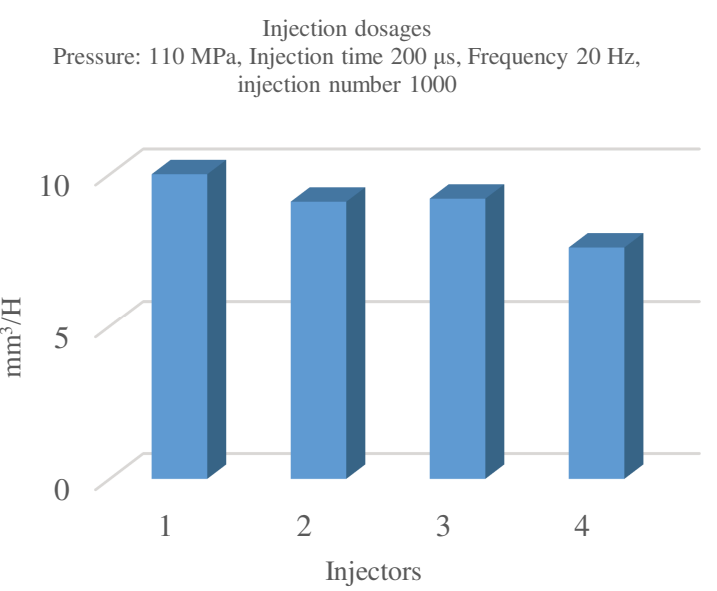

Fig. 19. Injector work test results. Pressure $110 \mathrm{MPa}$, injection time $200 \mu \mathrm{s}$

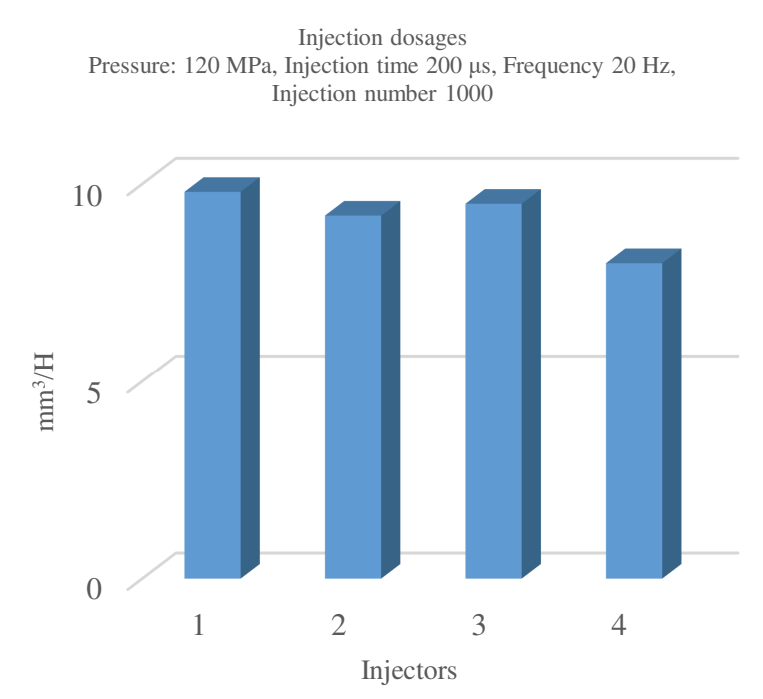

Fig. 20. Injector work test results. Pressure $120 \mathrm{MPa}$, injection time $200 \mu \mathrm{s}$

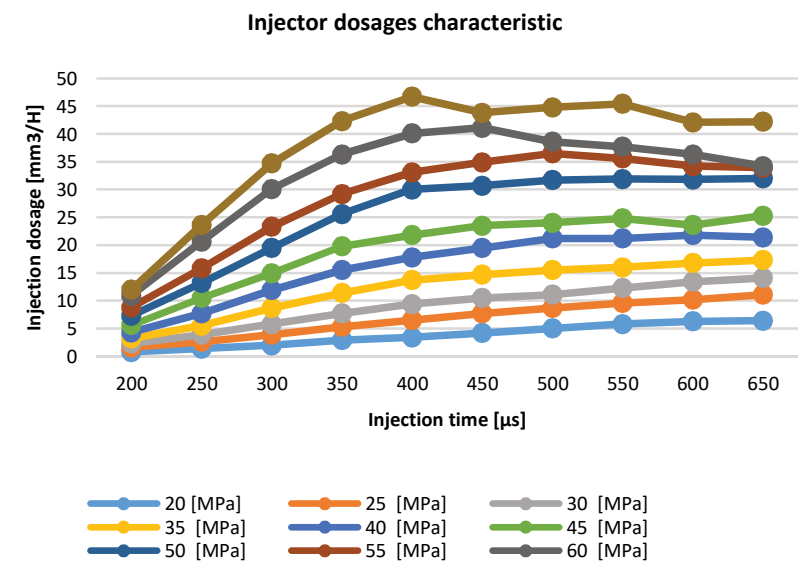

Fig. 21. Faulty injector work characteristic

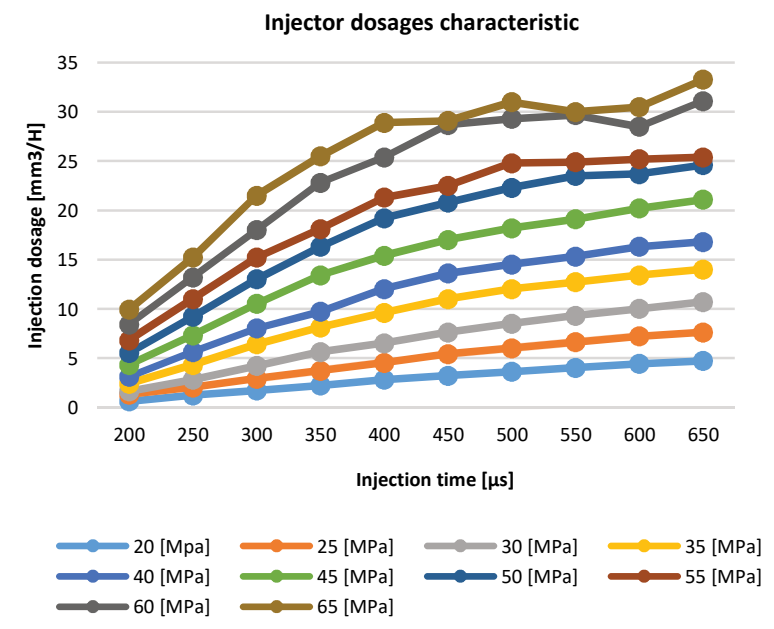

Fig. 22. Correct injector work characteristic

Fuel injectors work in varies dosages areas (Fig. 23). It means that every load of engine need appropriate fuel dosage by appropriate pressure. So that represents it has been 
made fuel injectors dosages areas graph. This graph came into being in results own researches. The first stage of the researches was measuring injection and return dosages. Test came out positive and according to researches injectors worked correctly. But the problem was with engine work and diagnose indicated on problem with injector. Problems with engine started by $1500 \mathrm{~min}^{-1}$.

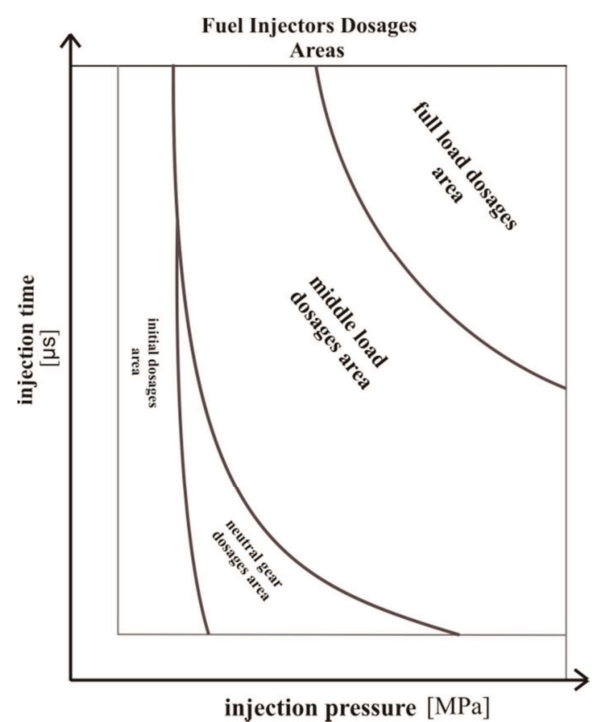

Fig. 23. Fuel injectors dosages areas [own study]

Engine work was irregular and it was heard strength clatting causing of predetonation combustion. One reason of detonation combustion is problem with initial dosages.
So that after standard injectors test has been made research to check initial dosage. Initial dosages occurs by short injection times with various pressures. For Continental injectors initial dosages have time $200 \mu$ s Electrical test is very important by researching fuel injectors. For piezoelectric it must be made insulation resistance by voltage $100 \mathrm{~V}$ between connectors and to mass by voltage $250 \mathrm{~V}$. Research showed that electrically injectors were correct.

\section{Conclusion}

The research objects were Continental fuel injectors. The research showed that detonation combustion and irregular engine work were caused to big initial injection dosage by $40-110 \mathrm{MPa}$ system pressure. The reason of it were improper piezoelectric element effect in first injector. Electric and standard test didn't reveal fuel injectors defects. Only accurate tests uncovered the problem. It has been made injectors work characteristics for initial dosages. The research shows that first injector dosage by $200 \mu$ s injection time in the 40-110 MPa range were too high. The research has been made for 300 and $400 \mu$ s injection time in the same pressure range and all injectors worked correctly. There are two ways to improve engine work. The first is change the injector and the second is disassemble, clean, assemble and try to regulate to properly screw in piezoelectric element. The magnitude of injection dosages in Continental fuel injectors depends on piezoelectric element tighten moment. It is hard to make the regulation on account of element huge sensitive.

\section{Nomenclature}

CI compression ignition

CR common rail system $\mu$ micro seconds

$\mathrm{H}$ one injection

\section{Bibliography}

[1] AMBroziK, A., AMBrozIK, T., ŁAGOWSKI, P. Fuel impact on emissions of harmful components of the exhaust gas from the CI engine during cold start up. Eksploatacja $i$ Niezawodnosc-Maintenance and Realiability. 2015, 17(1), 95-99.

[2] GÜNTHER, H. Common Rail - Systeme in der Werkstattpraxis. Technik, Prüfung, Diagnose. Bad Wörihofen: Krafthand Verlag Walter Schultz GmbH. 2012.

[3] KNEFEL, T. Ocena techniczna wtryskiwaczy Common Rail na podstawie doświadczalnych badań przelewów. Eksplo- atacja i Niezawodnosc-Maintenance and Reliability. 2012, 14(1), 42-53.

[4] OSIPOWICZ, T., ABRAMEK, K.F., STOECK, T. Testing of modern common rail fuel injectors. Combustion Engines. 2015, 162(3), 688-694.

[5] OSIPOWICZ, T. Diagnosing Common Rail fuel injectors using fuel micro - doses. Teka. Commission of Motorization and Energetics in Agriculture. 2015, 15(1), 61-64.

[6] OSIPOWICZ, T. Analysis of the costs and cost - efficiency of regeneration of modern fuel injection systems in CI engines. Econtechmod. An International Quarterly Journal. 2016, 5(2), 45-50.
Tomasz Osipowicz, DEng. - Faculty of Mechanical Engineering and Mechatronics at West Pomeranian University of Technology.

e-mail: Tomasz.Osipowicz@zut.edu.pl

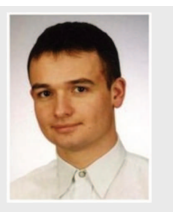

Karol F. Abramek, DSc., DEng. - Faculty of Mechanical Engineering and Mechatronics at West Pomeranian University of Technology. e-mail: Karol.Abramek@zut.edu.pl 